\title{
Design and Evaluation of E-Shaped Microstrip Patch Antenna (MPA) For Wimax Application
}

\author{
S.Alagarsamy \\ Sethu Inst. of Tech., \\ Pulloor - 626115, \\ Tamilnadu, India
}

\author{
Vasant Naidu \\ Sethu Inst. of Tech., \\ Pulloor - 626115, \\ Tamilnadu, India
}

\author{
P.Immanuel Vinoth \\ Sethu Inst. of Tech., \\ Pulloor - 626115, \\ Tamilnadu, India
}

\author{
M.Pandimadevi \\ Sethu Inst. of Tech., \\ Pulloor - 626115, \\ Tamilnadu, India
}

\begin{abstract}
A novel material - Mg Ferrite doped with Samarium (Sm), Dysprosium (Dy) was synthesised through sol-gel route. This novel ferrite material showed a very low value of $\varepsilon_{\mathrm{r}}(2.8)$. This ferrite material was sandwitched between the FR-4 substrates and a Microstrip patch antenna (MPA) was designed by using electromagnetic simulator IE3D software. The function of radiating element was analysed, by determining the return loss, voltage standing wave ratio (VSWR), directivity, gain and efficiency. The results showed that the antenna had an acceptable performance with VSWR $\leq 2$, return loss of $9.799 \mathrm{~dB}$, this was obtained by using a $50 \mathrm{ohms}$ feed line and with a certain level of geometry tuning over the patch to resonate at the desired frequency. The geometry tuning of about 5\% compared to the actual sizes required to resonate at a frequency range of $3.5 \mathrm{GHz}$.
\end{abstract}

\section{Keywords}

Lanthanides doped ferrite, MPA, VSWR and IE3D

\section{INTRODUCTION}

The main aim of next generation wireless communication is high-speed networking service for multimedia communication. The need for wireless communications has increased rapidly in recent years demanding quality of service, security, handover, and increased throughput for high speed working networks [1]. Microstrip patch antenna consists of a radiating patch on one side of a dielectric substrate which has a ground plane on the other side. They are very popular due to their low profile, lowcost, ease of fabrication, bandwidth, and radiation properties. The patch is generally square, rectangular, circular, triangular, and elliptical [2,3]. However, their narrow bandwidth is a drawback, to overcome this draw back of bandwidth enhancement of the antennas, few techniques have been reported, by surface meandering, making slots, aperture coupled patches or by near frequency resonators $[4,5]$. By increasing the substrate height, this problem can be sorted out, but this creates the appearance of surface waves, which causes a reduction in antenna efficiency [6]. This paper presents a proposal of E-shaped patch antenna design with the novel substrate material to match the impedance with the microstrip transmission feed line.

The MPA design comprises of Sm-Dy doped Magnesium ferrite sandwidched between FR4 plates [7] with a thickness of $2.38 \mathrm{~mm}$ to cover the WiMAX range, for a frequency range of $3.5 \mathrm{GHz}$. The MPA required has undergone a size reduction factor of $5 \%$ compared to the actual size to resonate at the WiMAX frequency.

\section{MPA MODELLING}

The antenna was fabricated by using lanthanides (Dy-Sm) doped Magnesium ferrite with very low dielectric constant $\varepsilon_{\mathrm{r}}=$ 2.8 and thickness of $2.38 \mathrm{~mm}$ was sandwitched between FR4 substrates. The dimensions of the patch such as length and width was calculated by using the formulas given in $[8$ 9],

2.1Calculation of the Width (W):

The width of the patch element (W) is given by.

$$
\mathrm{W}=\frac{\mathrm{C}}{2 \mathrm{f}_{0} \sqrt{\frac{\left(\mathrm{er}_{\mathrm{r}}+1\right)}{2}}}
$$

\subsection{Calculation of Effective dielectric constant ( $\varepsilon$ reff ):}

The effective of the dielectric constant $\left(\varepsilon_{\text {reff }}\right)$ depending on the same geometry $(\mathrm{W}, \mathrm{h})$ but is surrounded by a homogeneous dielectric of effective permittivity $\varepsilon_{\text {reff }}$, whose value is determined by evaluating the capacitance of the fringing field.

$\epsilon_{\text {reff }}=\frac{\epsilon_{\mathrm{r}}+1}{2}+\frac{\epsilon_{\mathrm{r}}-1}{2}\left[1+12 \frac{\mathrm{h}}{\mathrm{w}}\right]^{\frac{1}{2}}$

\subsection{Calculation of the Effective length ( eff $L$} ):

$\mathrm{L}_{\text {eff }}=\frac{\mathrm{C}}{2 \mathrm{f}_{0 \sqrt{\epsilon_{\text {reff }}}}}$

\subsection{Calculation of the length extension $(\Delta L)$ :}

$\Delta \mathrm{L}=0.412 \mathrm{~h} \frac{\left(\epsilon_{\text {reff }}+0.3\right)\left(\frac{\mathrm{W}}{\mathrm{h}}+0.264\right)}{\left(\epsilon_{\text {reff }}-0.258\right)\left(\frac{\mathrm{W}}{\mathrm{h}}+0.8\right)}$

\subsection{The actual length (L) of patch}

$$
\mathrm{L}=\mathrm{L}_{\text {eff }}-2 \Delta \mathrm{L}
$$

Considering the thickness of the substrate to be $2.38 \mathrm{~mm}$, length was kept $19 \mathrm{~mm}$ and the width was $57 \mathrm{~mm}$, here the inset feed position was optimized from the simulation. Here the antenna geometry is given in Fig.1. It was found that the antenna was resonating at $3.7 \mathrm{GHz}$ for a very narrow band. To shift this resonating frequency to a desired range the patch geometry was tuned to a frequency of $3.7 \mathrm{GHz}$. 

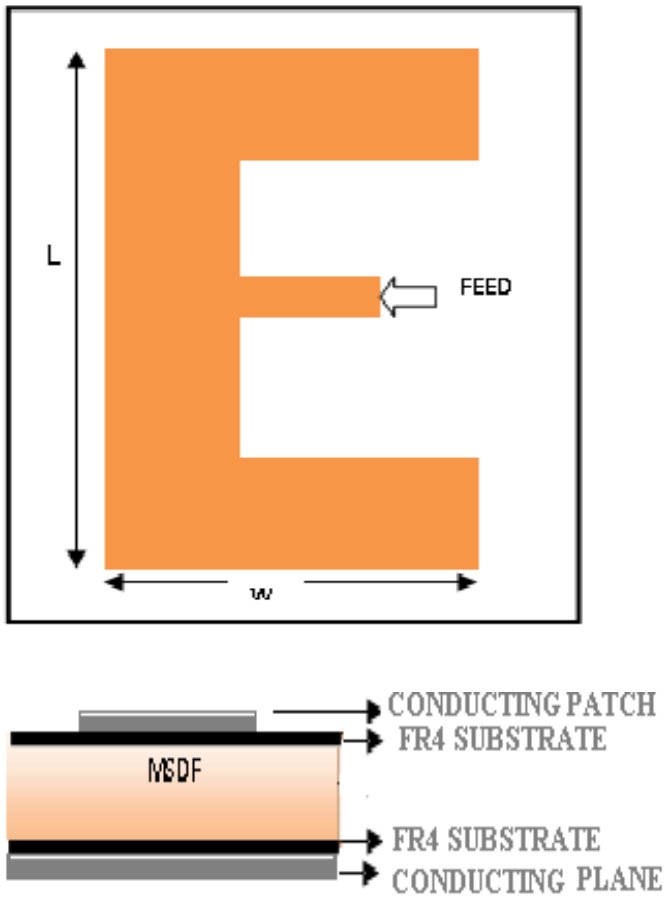

Fig.1 Top view and Side view of MPA

\section{SIMULATED RESULTS}

The simulation was performed using EM simulator IE3D[10], the results shows that $\mathrm{S} 11$ at resonating frequency as $-9.79 \mathrm{~dB}$ in Fig.2. The important property of any antenna is VSWR, in the proposed E-shaped MPA design the achieved value was, VSWR $<2$ at the resonating frequency in Fig.3. The impedance matching of the proposed antenna exhibits good matching in Fig.4. The gain of the E-shaped MPA over its operating frequency is of about $6.23 \mathrm{~dB}$ shown in Fig.5. The directivity of the antenna was $7.585 \mathrm{~dB}$ shown in Fig.6.

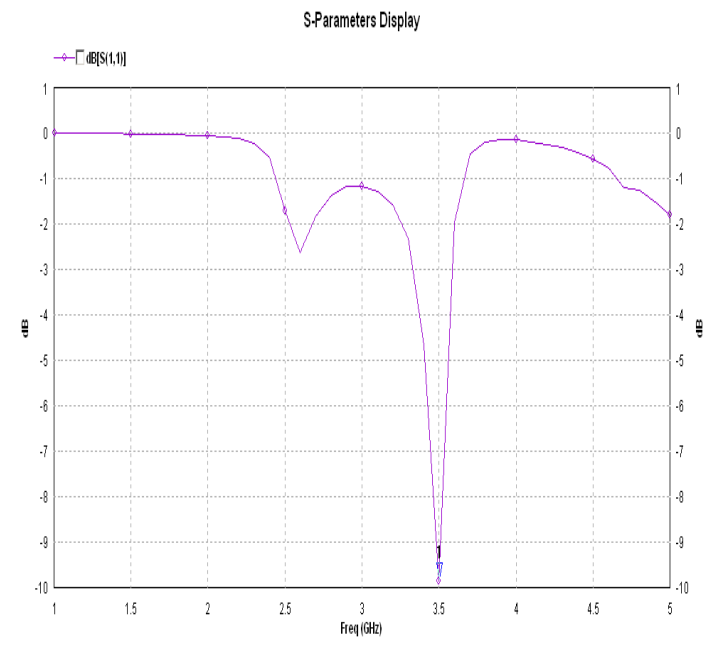

Figure .2 Return Loss (S11)

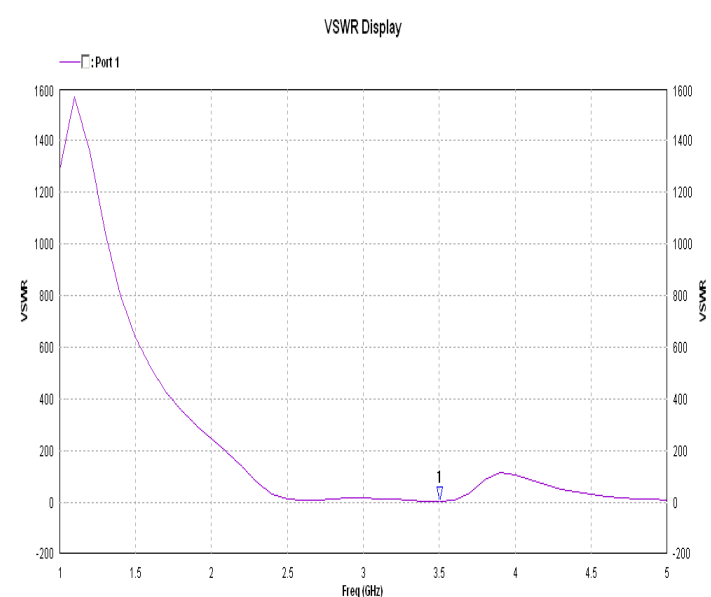

Figure.3 VSWR

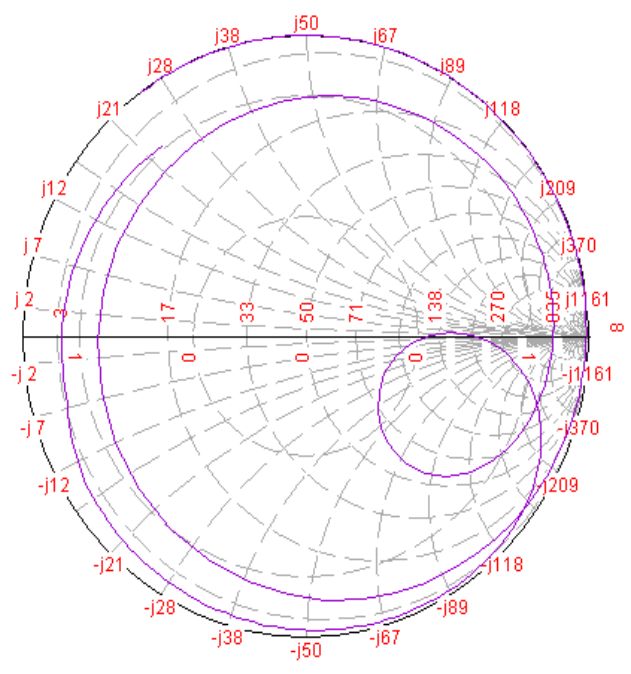

Smith-Chart Display

Figure.4 Impedance Matching

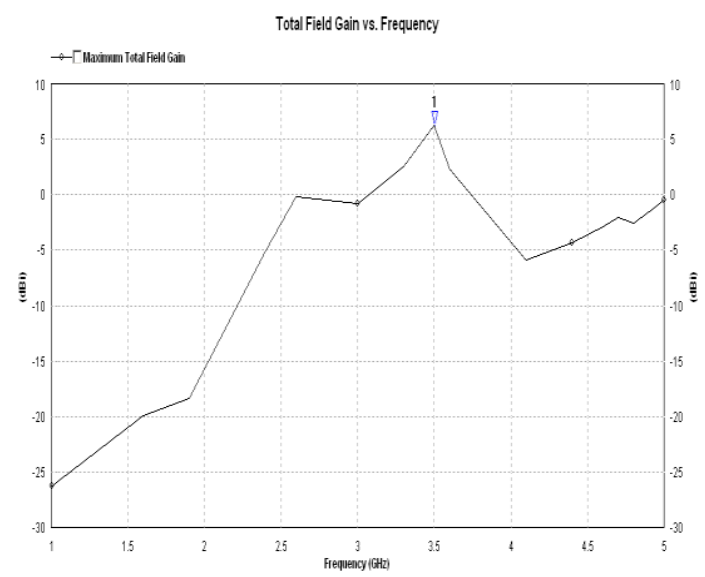

Figure.5 Gain 
Total Field Directivitys. Frequency

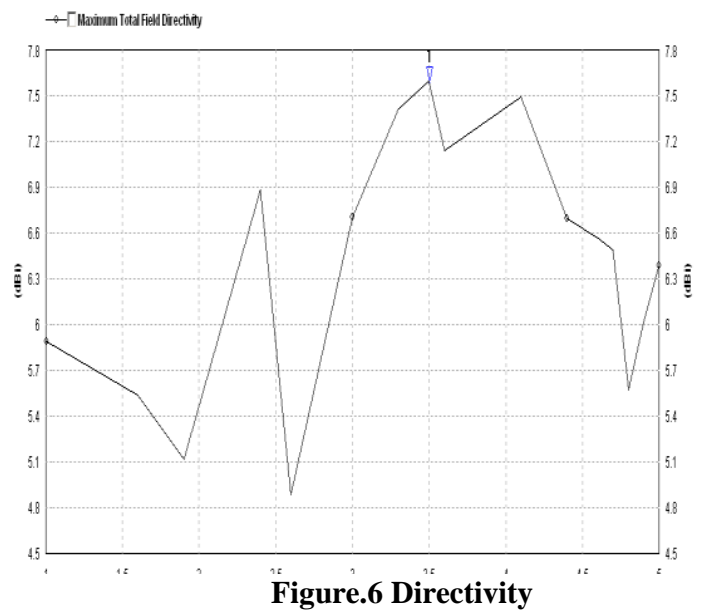

\subsection{Antenna Efficiency}

The antenna efficiency is maximum at resonate frequency and it is of $73.32 \%$ at $3.5 \mathrm{GHz}$ frequency also plotted with it the radiation efficiency which scales an $82.10 \%$ and it is shown below in Fig.7.

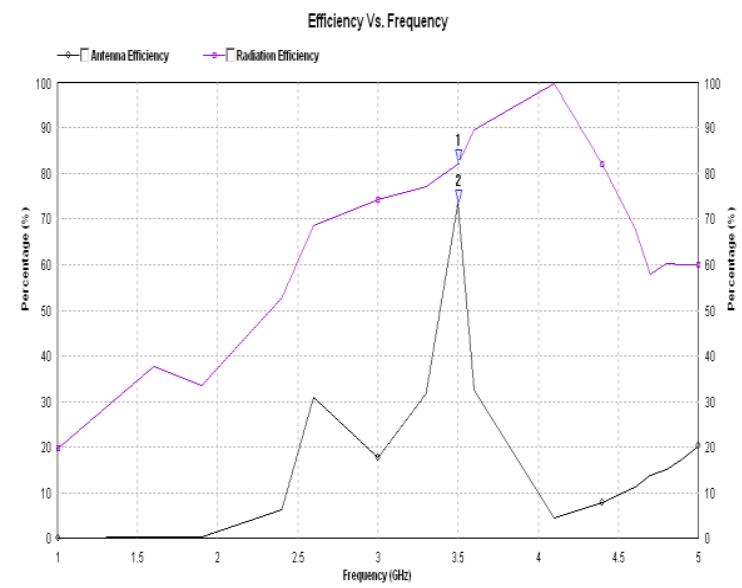

Figure.7 Efficiency

\subsection{Radiation Pattern}

The radiation pattern is defined as a mathematical function or a graphical representation of the radiation properties of the antenna as a function of space coordinates.

In most cases, the radiation pattern is determined in the farfield region and is represented as function of the directional coordinates [11-12]. The radiation pattern obtained here is broadside radiation in polar and Cartesian form as displayed in Fig.8 and Fig.9.

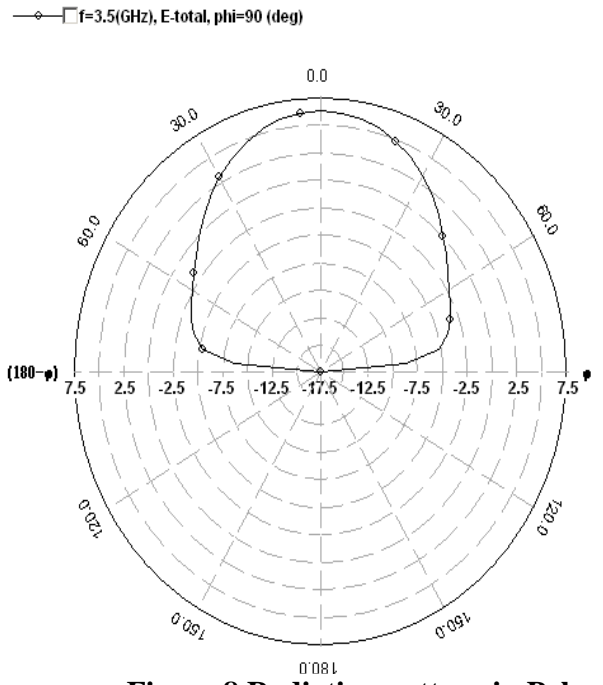

Figure.8 Radiation pattern in Polar plot

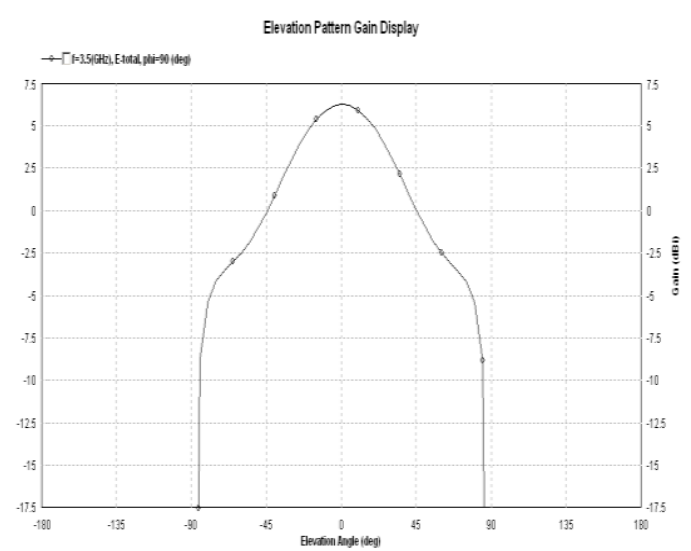

Figure.9 Radiation pattern in Cartesian plot

The dimensions and some parameters are tabulated in the table given below.

Table.1. Parametric of the designed MPA

\section{PARAMETRICS OF MPA}

\begin{tabular}{ll}
\hline Patch length & $19 \mathrm{~mm}$ \\
\hline Patch Width & $57 \mathrm{~mm}$ \\
\hline Height of the substrate & $2.38 \mathrm{~mm}$ \\
\hline Size reduction & $5 \%$ \\
\hline Impedance matching & $50 \Omega$ \\
\hline S11 & $-9.8 \mathrm{~dB}$ \\
\hline Gain & $6.23 \mathrm{~dB}$ \\
\hline
\end{tabular}




\begin{tabular}{ll}
\hline Directivity & $7.58 \mathrm{~dB}$ \\
\hline Antenna Efficiency & $73.32 \%$ \\
\hline Radiation Efficiency & $82.10 \%$ \\
\hline
\end{tabular}

\section{CONCLUSION}

In this paper a novel Lanthanides (Dy-Sm) doped Magnesium ferrite substrate was used for antenna miniaturization with enhanced bandwidth performance. Analytical and numerical analysis were carried out to demonstrate the basic concept, design procedure, and model verifications. In our design we achieved the impedance matching between the radiating patch and the transmission feed line. There acceptable parametric outcomes such like the Return Loss (S11), Gain, Directivity, Antenna Efficiency and Radiation Efficiency for the E-shaped MPA is tabulated in Table 1. The lanthanides doped Magnesium ferrite antenna has been matched to $50 \Omega$ impedance in the frequency range covering WiMAX operational band having good efficiency assets. This constitutes the highest bandwidth, gain, and efficiency reported for such a small size thin planar antenna.

Our results show that the designed lanthanides doped Magnesium ferrite antenna-substrate for MSP is a good candidate for space constrained WiMAX operational band systems. With further improvements to its efficiency and gain, a topic of ongoing investigations, this lanthanides doped Magnesium ferrite antenna could become an ideal candidate for future WiMAX systems.

\section{REFERENCES}

[1] Jagdish. M. Rathod, Comparative Study of Microstrip Patch Antenna for Wireless Communication Application, International Journal of Innovation, Management and Technology, Vol. 1, No. 2, June 2010.

[2] R. Garg, Microstrip Antenna Design Handbook, Artech House, Boston, Mass, USA, 2001.
[3] K.L. Wong, Compact and Broadband Microstrip Antenna , JohnWiley \& Sons, New York, NY, USA, 2002.

[4] C. A. Balanis, Antenna Theory Analysis and Design, John Wiley and Sons. Inc, 1982.

[5] Salai Thillai Thilagam, Design and Comparison of Microstrip Slot Antennas, IJECT Vol.2, Issue 4, Oct. Dec.2011

[6] Neenansha Jain, E-Shape Micro strip Patch Antenna on Different Thickness for pervasive Wireless Communication, International Journal of Advanced Computer Science and Applications, Vol. 2, No. 4, 2011.

[7] Designing a dual ISM band implantable antenna for medical monitoring applications using Dy- Sm doped magnesium Nano Ferrite material International Journal of Computer Applications (0975 - 8887) ,Vol 44, No 12, Page 1-4.

[8] Vasant Naidu et.al "Mg Sm Ferrite for Nano structured E-Shaped Patch Antenna studies" Int. J.Com.Appl, Volume 30- No.5,pp 45-50, Sept 2011.

[9] Vasant Naidu et.al "Sm- Gd doped Magnesium Ferrite for E-shaped Microstrip Patch Antenna” International Journal of Computer Applications Volume 35- No.4, December 2011.

[10] Jibendu Sekhar Roy, Compact and Broadband Microstrip Antennas for Next Generation High-Speed Wireless Communication, International Journal of Microwave Science and Technology, Volume 2007.

[11] A. Babar, Planar Inverted Miniaturized E Antnna, for Compact Wireless Systems, IEEE, 2009.

[12] Anubhuti Khare, New Multiband E-Shape Microstrip Patch Antenna on RT DUROID 5880 Substrate and RO4003 Substrate for Pervasive Wireless Communication, International Journal of Computer Applications (0975 $\quad-\quad 8887) \quad$ Volume9No.8,November2010. 